\title{
Cortisol and 17- $\alpha$-hydroxy-progesterone levels in infants with refractory hypotension born at 30 weeks of gestation or less
}

P.G. Martins and R.S. Procianoy
Serviço de Neonatologia, Departamento de Pediatria, Universidade Federal do Rio Grande do Sul and

Hospital de Clínicas de Porto Alegre, Porto Alegre, RS, Brasil

\begin{abstract}
Correspondence
R.S. Procianoy

Rua Tobias da Silva, 99

Conjunto 302

90570-020 Porto Alegre, RS

Brasil

Fax: +55-51-3331-2738

E-mail: renatosp@terra.com.br

Research supported by a grant from Hospital de Clínicas de Porto Alegre,

Research Incentive Fund (FIPE-HCPA),

$\ldots \ldots \ldots \ldots \ldots \ldots$
\end{abstract}

Received May 23, 2006

Accepted January 26, 2007

\begin{abstract}
Refractory hypotension is frequent in very low-birth weight infants, whose hypothalamic-pituitary-adrenal axis has been suggested to be immature. The objective of the present study was to evaluate basal cortisol and 17- $\alpha-\mathrm{OH}$-progesterone in the first $36 \mathrm{~h}$ of life in preterm infants with and without refractory hypotension (mean arterial blood pressure below the lower limit for gestational age throughout the study despite aggressive volume expansion and use of vasopressors). Thirtyfive infants with $\leq 30$ weeks of gestation and a birth weight $\leq 1250 \mathrm{~g}$, with no postnatal use of corticosteroid or death in the first $48 \mathrm{~h}$ were studied. Mean arterial pressure was measured every $4 \mathrm{~h}$ during the first $48 \mathrm{~h}$. Cortisol and 17- $\alpha-\mathrm{OH}-$ progesterone were determined at 12 and $36 \mathrm{~h}$ and patients were divided into refractory hypotensive $(\mathrm{N}=15)$ and control $(\mathrm{N}=20)$ groups. The groups were not different regarding type of delivery, use of prenatal corticosteroid, requirement of mechanical ventilation, use of vasopressor drugs, morphine, fentanyl, prophylactic indomethacin, and mean sample timing. Although refractory hypotensive newborns were more immature, were smaller, suffered more deaths after $48 \mathrm{~h}$ of life and had a higher SNAPPE-2 score, their cortisol and $17-\alpha-\mathrm{OH}$-progesterone levels were not different from controls at $12 \mathrm{~h}$ and at $36 \mathrm{~h}$. The increase of cortisol in newborns with refractory hypotension $36 \mathrm{~h}$ after birth was significantly higher than in controls. Despite the fact that refractory hypotensive very low-birth weight neonates were submitted to a very stressful condition, their cortisol and $17-\alpha-\mathrm{OH}-$ progesterone levels were similar to controls.
\end{abstract}

Key words

- Hypotension

- Extremely preterm infant

- Adrenal insufficiency

- Cortisol

\section{Introduction}

A significant proportion of very lowbirth weight (VLBW) infants may present hypotension that is refractory to both volume expanders and vasopressor drugs $(1,2)$. Many of these infants have been shown to respond to the use of corticosteroids, with normalization of arterial blood pressure and a reduction of the dose of vasopressor drugs (3-7).

Although Hanna et al. (8) have reported that very preterm newborn infants have a normal pituitary response to ovine cortico- 
tropin-releasing hormone and a normal adrenal response to ACTH, recent studies have shown that those with refractory hypotension have an immature hypothalamic-pituitary-adrenal (HPA) axis and a decreased response to the ACTH test compared to VLBW infants with no refractory hypotension at the end of the first week of life $(1,2)$. Watterberg et al. (9) also suggested that VLBW infants have decreased capacity to synthesize cortisol and present an elevated concentration of cortisol precursors like 17$\alpha$-hydroxy-progesterone (17- $\alpha$-OH-progesterone) after the ACTH stimulation test.

Hypotension is an early manifestation in VLBW infants, usually in the first $48 \mathrm{~h}$ of life, and is associated with increased mortality and central nervous system morbidity in preterm infants (10-12). Studies on the HPA axis with corticotropin-releasing hormone or ACTH have conducted on very preterm infants from the 4th to the 15th day of life $(1,2,8,9)$. There is no study evaluating basal serum cortisol levels in VLBW infants with and without refractory hypotension during the critical period for refractory hypotension, i.e., the first $48 \mathrm{~h}$ of life. An adrenal response to a stressful situation like severe arterial hypotension resistant to inotropic treatment is expected in VLBW infants with an intact HPA axis (13).

We measured serum cortisol and 17- $\alpha$ $\mathrm{OH}$-progesterone levels without any HPA axis stimulation test, 12 and $36 \mathrm{~h}$ after birth in VLBW infants with and without refractory hypotension.

\section{Material and Methods}

The study protocol was approved by the Ethics Committee at Hospital de Clínicas de Porto Alegre, Brazil, and written informed consent was obtained from the infants' parents or guardians.

We conducted a prospective study that included all neonates with a gestational age of $\leq 30$ weeks and a birth weight of $\leq 1250 \mathrm{~g}$ delivered at the obstetric Unit of Hospital de Clínicas de Porto Alegre, Porto Alegre, RS, Brazil, and admitted to the neonatal intensive care unit between March 2004 and January 2005. The exclusion criteria were use of corticosteroids in the first $48 \mathrm{~h}$ of life, congenital infections, major congenital malformations, and death in the first $48 \mathrm{~h}$ of life.

Newborns were followed for the first 48 $\mathrm{h}$ of life, starting at $4 \mathrm{~h}$ of age, and their mean arterial blood pressure (MABP) was measured every $4 \mathrm{~h}$. Nurses who were blind to the study measured MABP by the oscillometric method with an arm cuff width approximately $45 \%$ of the upper arm circumference, during a quiet or sleeping state. An average of three measurements was obtained each time.

At 12 and $36 \mathrm{~h}$, an additional blood sample $(0.5 \mathrm{~mL})$ was collected from all newborns for cortisol and 17- $\alpha-\mathrm{OH}$-progesterone measurements. The time of day when the sample was collected does not modify the results obtained because the circadian rhythm is not present in newborn infants. No venous puncture was performed only for the purposes of the study. Rather, blood samples were collected at the time of routine laboratory exams. Blood was immediately centrifuged and serum was stored at $-80^{\circ} \mathrm{C}$ because the hormones were measured in a single assay after the end of the study. Patients were assisted by their neonatologists who were not involved in the study and who were blind to cortisol and 17- $\alpha-\mathrm{OH}$-progesterone levels. The authors were not responsible for the care of the newborns.

Newborns were divided into two groups: refractory hypotensive and control. Refractory hypotensive newborns were those whose MABP remained below the lower limit for gestational age $(14,15)$ throughout the study, with signs of hypoperfusion such as poor capillary return despite the use of aggressive volume expansion (at least $10 \mathrm{~mL} / \mathrm{kg}$ three times over $30 \mathrm{~min}$ ) and vasopressor drugs (dopamine up to $20 \mu \mathrm{g} \mathrm{kg}^{-1} \mathrm{~min}^{-1}$ and/or 
dobutamine up to $20 \mu \mathrm{g} \mathrm{kg}^{-1} \mathrm{~min}^{-1}$ ). Controls were newborns with MABP within the normal range for gestational age or hypotensive newborns who responded to the use of volume expansion and/or vasopressor drugs.

Cortisol was measured by ECLIA using the Elecsys 1010/2010/Modular Analytics E170 (Roche Diagnostics GmbH, Mannheim, Germany), and $17-\alpha-\mathrm{OH}-$ progesterone by radioimmunoassay using the ImmunoChem Coated Tube-125/RIA (INC Biomedicals, Inc., Diagnostics Division, Costa Mesa, CA, USA). The lower detection limits were 0.036 $\mu \mathrm{g} / \mathrm{dL}$ and $0.1 \mathrm{ng} / \mathrm{mL}$ for cortisol and $17-\alpha-$ $\mathrm{OH}$-progesterone, respectively. Intra-assay and interassay coefficients of variation were 1 and $1.8 \%$ for cortisol, and 7.8 and $9.8 \%$ for $17-\alpha-\mathrm{OH}-$ progesterone. The person who did all laboratory determinations was blind to the study. All samples were tested in duplicate at the same time.

A sample size of 12 patients in each group was calculated based on an effect size of 1.5, a level of significance of 0.05 and power of 0.9. Since logarithmic transformation was used for comparison of cortisol and $17-\alpha-\mathrm{OH}$-progesterone, we were able to use the following parametric tests: Student $t$-test and analysis of variance (ANOVA). The chi-square and Fischer exact tests were also used. Spearman correlation was calculated for gestational age, birth weight and cortisol at 12 and $36 \mathrm{~h}$ and for gestational age, birth weight and $17-\alpha-\mathrm{OH}-$ progesterone at 12 and $36 \mathrm{~h}$.

\section{Results and Discussion}

During the study period, 40 newborns with a gestational age of 30 weeks or less and a birth weight of $1250 \mathrm{~g}$ or less were delivered at our institution. Three were excluded: 1 with major multiple congenital malformations and 2 who died within the first $24 \mathrm{~h}$. Two were lost (birth weights 450 and $505 \mathrm{~g}$ ) because it was impossible to collect blood samples for laboratory analy- sis. Therefore, a total of 35 patients were analyzed, 15 in the refractory hypotensive group and 20 in the control group. Hypotension was manifested within the first $12 \mathrm{~h}$. MABP was significantly lower in the refractory hypotensive group than in the control group throughout the study period.

Comparison of the two groups is shown in Table 1. There was no difference between groups regarding type of birth, prenatal corticosteroid use, mechanical ventilation requirement, and use of vasopressor drugs, morphine, fentanyl, and prophylactic indomethacin. None of the patients in either group had positive blood and/or cerebrospinal fluid cultures during the study period. The mean sample timings were similar for both groups. Mean gestational age and birth weight were lower in the refractory hypotensive group than in the control group. SNAPPE-2 and

Table 1. Characteristics of the study population.

\begin{tabular}{|c|c|c|}
\hline & $\begin{array}{l}\text { Refractory hypotensive } \\
\qquad(\mathrm{N}=15)\end{array}$ & $\begin{array}{l}\text { Control } \\
(\mathrm{N}=20)\end{array}$ \\
\hline Birth weight $(g)^{a}$ & $690 \pm 176^{*}$ & $1041 \pm 164$ \\
\hline Gestational age (weeks) ${ }^{\mathrm{a}}$ & $27.02 \pm 1.6^{*}$ & $29.4 \pm 0.8$ \\
\hline Cesarean section ${ }^{b}$ & $6(40 \%)$ & $5(25 \%)$ \\
\hline Rupture of membranes $>18 \mathrm{~h}^{\mathrm{c}}$ & $12(80 \%)$ & $19(95 \%)$ \\
\hline Prenatal corticosteroid (number of doses) & $1.3 \pm 1.7$ & $1.4 \pm 1.7$ \\
\hline Prenatal corticosteroid (number of patients) ${ }^{b}$ & $5(33 \%)$ & $10(50 \%)$ \\
\hline Mechanical ventilation ${ }^{c}$ & $14(93 \%)$ & $18(90 \%)$ \\
\hline Use of dopamine ${ }^{c}$ & $14(93 \%)$ & $18(90 \%)$ \\
\hline Use of dobutamine ${ }^{b}$ & $8(53 \%)$ & $5(25 \%)$ \\
\hline Use of morphine ${ }^{c}$ & $1(7 \%)$ & $0(0 \%)$ \\
\hline Use of fentanylc & $4(27 \%)$ & $3(15 \%)$ \\
\hline Prophylactic indomethacin ${ }^{b}$ & $10(67 \%)$ & $10(50 \%)$ \\
\hline SNAPPE-2 ${ }^{\mathrm{a}}$ & $57.9 \pm 21.6^{*}$ & $18.4 \pm 15.0$ \\
\hline First sample timing $(\mathrm{h})^{\mathrm{a}}$ & $13.2 \pm 7.4$ & $13.9 \pm 6.5$ \\
\hline Second sample timing $(h)^{a}$ & $33.3 \pm 9.1$ & $33.6 \pm 7.5$ \\
\hline Cortisol $12 \mathrm{~h}(\mu \mathrm{g} / \mathrm{dL})^{\mathrm{d}}$ & $12.8 \pm 15.9^{+}$ & $15.7 \pm 29.7$ \\
\hline Cortisol $36 \mathrm{~h}(\mu \mathrm{g} / \mathrm{dL})^{\mathrm{d}}$ & $25.7 \pm 28.9$ & $18.1 \pm 28.6$ \\
\hline 17- $\alpha-\mathrm{OH}$-progesterone $12 \mathrm{~h}(\mathrm{ng} / \mathrm{mL})^{\mathrm{d}}$ & $32.1 \pm 22.9$ & $23.1 \pm 14.0$ \\
\hline 17- $\alpha-\mathrm{OH}$-progesterone $36 \mathrm{~h}(\mathrm{ng} / \mathrm{mL})^{\mathrm{d}}$ & $49.7 \pm 44.3$ & $26.6 \pm 17.3$ \\
\hline Death after $48 \mathrm{~h}^{\mathrm{c}}$ & $10(67 \%)^{*}$ & $3(15 \%)$ \\
\hline
\end{tabular}


number of deaths after $48 \mathrm{~h}$ of life were significantly higher in the refractory hypotensive group than in the control group. There were no significant differences between groups regarding cortisol at $12 \mathrm{~h}$ and $17-\alpha-$ $\mathrm{OH}$-progesterone levels at 12 and $36 \mathrm{~h}$. There was a trend to higher cortisol levels at $36 \mathrm{~h}$ in the refractory hypotensive newborns compared to controls. Cortisol levels at $36 \mathrm{~h}$ were significantly higher than at $12 \mathrm{~h}$ in the refractory hypotensive group. This difference was not present in the control group, nor was it observed for $17-\alpha-\mathrm{OH}$-progesterone in either group. The increase of cortisol from 12 to $36 \mathrm{~h}$ in the refractory hypotensive group was significantly higher than in the control group.

There were no statistically significant correlations between gestational age or birth weight and cortisol at 12 and $36 \mathrm{~h}$ and between gestational age or birth weight and $17-\alpha-\mathrm{OH}$-progesterone at 12 and $36 \mathrm{~h}$.

It was expected that sick, stressed patients would respond with increased cortisol levels (13) but this was not the case. Cortisol levels were similar in both groups at $12 \mathrm{~h}$ of life, even though refractory hypotensive neonates were sicker than controls, as demonstrated by the significantly higher number of deaths after $48 \mathrm{~h}$ of life and higher SNAPPE2 scores.

Early in gestation, maternal cortisol freely crosses an immature placenta. Later in gestation, as placenta metabolism matures, maternal cortisol is oxidized to its inactive metabolite, cortisone. The negative feedback from maternal cortisol decreases, leading to increased fetal synthesis. If the immature newborn lacks the capacity to synthesize cortisol, accumulation of cortisol precursors like 17- $\alpha$-OH-progesterone occurs (16).

Previous studies have suggested that VLBW infants with refractory hypotension have a decreased capacity to synthesize cortisol $(1,2,17)$. Therefore, we expected to find accumulation of cortisol precursors, especially $17-\alpha-\mathrm{OH}-$ progesterone, in this group; however, there was no difference between groups. This lack of difference may be explained by the fact that we did not perform HPA stimulation tests as done by previous investigators $(2,8,9)$ or by the presence of $17-\alpha-\mathrm{OH}$-progesterone of maternal origin in the circulation of the newborns studied. Our objective was to study spontaneous cortisol and $17-\alpha-\mathrm{OH}-$ progesterone behavior in the first $36 \mathrm{~h}$ of life in refractory hypotensive VLBW infants and compare them to controls.

Studies on cortisol levels in VLBW infants have been performed after the fourth day of life to allow maternal hormones to be metabolized (Ng et al. (2) on day 7, and Jett et al. (18) between day 4 and day 6). However, the critical period for severe hypotension in VLBW infants is the first $48 \mathrm{~h}$ (19). Recently $\mathrm{Ng}$ et al. (2) published the first blind clinical trial on the use of hydrocortisone for the treatment of refractory hypotension in preterm infants. In the cited study, the median age of commencement of the trial medication (hydrocortisone or placebo) was $11 \mathrm{~h}$ of life, suggesting that corticosteroid deficiency might be present already in the first $12 \mathrm{~h}$ of life (7). There is no study following cortisol and 17- $\alpha-\mathrm{OH}$-progesterone levels in the first $48 \mathrm{~h}$ in refractory hypotensive newborns $\leq 30$ weeks gestation. Our study showed that there was a cortisol increase on the second day of life in refractory hypotensive neonates, probably in response to the high stress situation, but the increase was not sufficient to keep blood pressure at normal levels. Adrenergic receptor down-regulation or nitric oxide synthesis deregulation in refractory hypotensive very preterm infants deserves further investigation.

The present study was an observational uncontrolled study. Management of the patients was the responsibility of the attending neonatologists, who were not involved in the study. Some patients received vasopressor drugs because of poor capillary return 
even though they did not present clinical hypotension. However, the prevalence of refractory hypotension found in our population was within the expected values. $\mathrm{Ng}$ et al. (7) reported that $30 \%$ of infants born after $<32$ weeks of gestation and with a birth weight of $<1500 \mathrm{~g}$ had refractory hypotension. Our study was restricted to infants with a birth weight of $\leq 1250 \mathrm{~g}$ and a gestational age of $\leq 30$ weeks, and the prevalence of refractory hypotension was $42 \%$.

Circadian rhythm is not present in the newborn infant, and VLBW infants show little pulsatility in their plasma cortisol over time. Therefore, a single random plasma cortisol level is representative of the plasma cortisol levels over a prolonged period of time (18).

The absence of a significant correlation between gestational age and birth weight and either cortisol at 12 and $36 \mathrm{~h}$ of life or $17-\alpha-\mathrm{OH}$-progesterone at 12 and $36 \mathrm{~h}$ of life suggests that there is no relationship between newborn maturity and these hormone levels in neonates born after $\leq 30$ weeks of gestation. Although Scott and Watterberg (17) suggested that there was an inverse relationship between cortisol level and gestational age when they studied newborn infants from 24 to 36 weeks of gestational age, Mesiano and Jaffe (20) suggested that the human fetal adrenal cortex does not produce cortisol de novo from cholesterol until about 30 weeks of gestation. After birth, the placental substrate is no longer available, and the VLBW infants will not have the enzymes required for de novo cortisol synthesis. This may explain the lack of correlation between maturity and cortisol and 17- $\alpha-\mathrm{OH}-$ progesterone in infants with a gestational age of $\leq 30$ weeks. Our study population was situated in a very narrow range of gestational age, around 28 weeks.

Although the standards for the diagnosis of hypotension in VLBW infants in the first $48 \mathrm{~h}$ of life are based on invasive measurements, the oscillometric method has a high correlation with direct intra-arterial monitoring in neonates, with a slight overestimation of blood pressure in VLBW infants. There is no correction factor to be used when arterial blood pressure is measured by the oscillometric method. A number of studies have compared the automated oscillometric method with direct intra-arterial blood pressure monitoring in neonates and have found a high correlation between mean blood pressure measurements by these two methods, with correlation coefficients ranging from 0.85 to 0.97 (21). In order to minimize errors in noninvasive MABP measurement it is suggested to choose an appropriate size cuff, to obtain blood pressure during a quiet or sleeping state, and to obtain an average of three measurements $(21,22)$. Our refractory hypotensive patients presented low MABP throughout the study period despite the use of volume expansion and vasopressor drugs. Therefore, there is no doubt about the hypotensive status of these neonates.

Our data showed that cortisol and 17- $\alpha-$ $\mathrm{OH}$-progesterone levels were similar in infants with refractory hypotension born after 30 weeks of gestation or less and with a birth weight of $1250 \mathrm{~g}$ or less and controls in the first $36 \mathrm{~h}$ of life, despite the fact that refractory hypotensive neonates were submitted to a very stressful condition.

\section{Acknowledgments}

We thank Prof. Mario Wagner (UFRGS) for assistance with the statistical analysis. 


\section{References}

1. Ng PC, Lam CW, Fok TF, Lee CH, Ma KC, Chan IH, et al. Refractory hypotension in preterm infants with adrenocortical insufficiency. Arch Dis Child Fetal Neonatal Ed 2001; 84: F122-F124.

2. Ng PC, Lee CH, Lam CW, Ma KC, Fok TF, Chan IH, et al. Transient adrenocortical insufficiency of prematurity and systemic hypotension in very low birthweight infants. Arch Dis Child Fetal Neonatal Ed 2004; 89: F119-F126.

3. Bourchier D, Weston PJ. Randomised trial of dopamine compared with hydrocortisone for the treatment of hypotensive very low birthweight infants. Arch Dis Child Fetal Neonatal Ed 1997; 76: F174-F178.

4. Gaissmaier RE, Pohlandt F. Single-dose dexamethasone treatment of hypotension in preterm infants. J Pediatr 1999; 134: 701-705.

5. Seri I, Tan R, Evans J. Cardiovascular effects of hydrocortisone in preterm infants with pressor-resistant hypotension. Pediatrics 2001; 107: 1070-1074.

6. Efird MM, Heerens AT, Gordon PV, Bose CL, Young DA. A randomized-controlled trial of prophylactic hydrocortisone supplementation for the prevention of hypotension in extremely low birth weight infants. J Perinatol 2005; 25: 119-124.

7. Ng PC, Lee CH, Bnur FL, Chan IH, Lee AW, Wong E, et al. A doubleblind, randomized, controlled study of a "stress dose" of hydrocortisone for rescue treatment of refractory hypotension in preterm infants. Pediatrics 2006; 117: 367-375.

8. Hanna CE, Keith LD, Colasurdo MA, Buffkin DC, Laird MR, Mandel $\mathrm{SH}$, et al. Hypothalamic pituitary adrenal function in the extremely low birth weight infant. J Clin Endocrinol Metab 1993; 76: 384-387.

9. Watterberg KL, Gerdes JS, Cook KL. Impaired glucocorticoid synthesis in premature infants developing chronic lung disease. Pediatr Res 2001; 50: 190-195.

10. Goldstein RF, Thompson RJ Jr, Oehler JM, Brazy JE. Influence of acidosis, hypoxemia, and hypotension on neurodevelopmental outcome in very low birth weight infants. Pediatrics 1995; 95: 238-243.

11. Watkins AM, West CR, Cooke RW. Blood pressure and cerebral haemorrhage and ischaemia in very low birthweight infants. Early
Hum Dev 1989; 19: 103-110.

12. Miall-Allen VM, de Vries LS, Dubowitz LM, Whitelaw AG. Blood pressure fluctuation and intraventricular hemorrhage in the preterm infant of less than 31 weeks' gestation. Pediatrics 1989; 83: 657661.

13. Lamberts SW, Bruining HA, de Jong FH. Corticosteroid therapy in severe illness. N Engl J Med 1997; 337: 1285-1292.

14. Lee J, Rajadurai VS, Tan KW. Blood pressure standards for very low birthweight infants during the first day of life. Arch Dis Child Fetal Neonatal Ed 1999; 81: F168-F170.

15. Development of audit measures and guidelines for good practice in the management of neonatal respiratory distress syndrome. Report of a Joint Working Group of the British Association of Perinatal Medicine and the Research Unit of the Royal College of Physicians. Arch Dis Child 1992; 67: 1221-1227.

16. Pepe GJ, Albrecht ED. Actions of placental and fetal adrenal steroid hormones in primate pregnancy. Endocr Rev 1995; 16: 608-648.

17. Scott SM, Watterberg KL. Effect of gestational age, postnatal age, and illness on plasma cortisol concentrations in premature infants. Pediatr Res 1995; 37: 112-116.

18. Jett PL, Samuels MH, McDaniel PA, Benda GI, LaFranchi SH, Reynolds JW, et al. Variability of plasma cortisol levels in extremely low birth weight infants. J Clin Endocrinol Metab 1997; 82: 2921 2925.

19. Dasgupta SJ, Gill AB. Hypotension in the very low birthweight infant: the old, the new, and the uncertain. Arch Dis Child Fetal Neonatal Ed 2003; 88: F450-F454.

20. Mesiano S, Jaffe RB. Developmental and functional biology of the primate fetal adrenal cortex. Endocr Rev 1997; 18: 378-403.

21. Nuntnarumit $P$, Yang W, Bada-Ellzey HS. Blood pressure measurements in the newborn. Clin Perinatol 1999; 26: 981-996.

22. Dannevig I, Dale HC, Liestol K, Lindemann R. Blood pressure in the neonate: three non-invasive oscillometric pressure monitors compared with invasively measured blood pressure. Acta Paediatr 2005; 94: 191-196. 